\title{
A CASE OF SEVERE VASCULAR INSUFFICIENCY OF THE LOWER EXTREMITIES TREATED BY SUBARACHNOID OSMOTIC NEUROLYSIS
}

\author{
J. S. NIELSEN, M.R.C.S., L.R.C.P., C.R.C.P.(C) ${ }^{\circ}$
}

Osmotic NEURoLYsis may be defined as the destruction of neuronal tissue by the use of hyperosmolar solutions. This technique followed the use of hypothermic isotonic solutions to produce neurolysis.

The use of hypothermic subarachnoid saline in the treatment of intractable pain was first described by Hitchcock in $1967^{1}$ and in that paper it was stated that it seemed the procedure was more likely to be a success in patients in whom posterior rhizotomy might be expected to be helpful.

In Hitchcock's original series of reported cases of cisternal hypertonic saline, pain relief was never accompanied by any demonstrable sensory loss and there was absence of bladder complications; this was confirmed by himself and others ${ }^{2}$ at a later date.

Hitchcock assumed that saline solution at $2^{\circ}$ to $4^{\circ} \mathrm{C}$ was hypertonic in relation to CSF, which presented the question: Was the effect due to low temperature of the perfusate, the osmolarity of the saline, or a combination of both?

Matthews ${ }^{2}$ presented a small series in which he measured the osmolarity of the injected cold saline and found that the most satisfactory results occurred in the patients receiving the solution of highest molality.

Hitchcock ${ }^{3}$ eventually used saline at temperatures between $4^{\circ} \mathrm{c}$ and $36^{\circ} \mathrm{c}$ and 7.5 per cent saline at room temperature via cisternal puncture in the treatment of seven patients with pain of advanced facial carcinoma. The results were encouraging; pain relief, with only transient side effects, lasted from 3 to 105 days and it seemed that the best results were obtained with the higher osmolalities, above 3,000 .

Recently, Stovall King et al., ${ }^{6}$ at the University of California working on dorsal roots of laminectomized cats showed that the chloride ion, as opposed to the osmotic effect, the temperature or the sodium ion played a major role in the establishment of the differential c fibre block when cat dorsal roots were perfused with hypertonic saline and that this block could be the mechanism of effect in the relief from pain following intrathecal perfusion of hypertonic solutions at room temperature.

\section{CASE History}

A 46-year-old female with a history of hypertension and intermittent claudication for the last five years presented in February 1971 because of severe claudication of both legs and gangrene of two toes of the left foot.

Femoral pulses were absent as was pulsation in all other peripheral arteries of the legs. The patient had continuous pain in the right ankle even at rest and was capable of walking only five yards before the ischaemic pain became too severe

\footnotetext{
'Department of Anaesthesia, University of Western Ontario and Victoria Hospital, London,
} Canada. 
to permit further exercise. Over the preceding three years she had undergone a right nephrectomy and three major arterial surgery procedures including aortofemoral bypass graft and sympathectomy.

From the point of view of vascular surgery everything possible had been done and amputations seemed to be the ultimate conclusion. ${ }^{4}$

Neurosurgical opinion ${ }^{5}$ for the treatment of the pain held out only the possibility of relief from cordotomy with the inherent possible complications of a bilateral procedure.

In view of the poor outlook in this case it was decided to perform subarachnoid osmotic neurolysis in order to obtain pain relief with the least possibility of complications.

\section{Procedure}

On March 25, 1971 the patient was taken to the operating room after premedication with meperidine, $75 \mathrm{mg}$, and atropine $0.6 \mathrm{mgm}$.

An intravenous infusion of 5 per cent dextrose in 0.2 per cent saline was started using a Mayo needle. The patient was placed in the right lateral position with a $5^{\circ}$ foot-down tilt and a number 22-gauge spinal needle was inserted through the dura at the lumbar 3 to 4 interspace.

Twenty millilitres of cerebral spinal fluid was aspirated, discarded and replaced with $15 \mathrm{ml}$ of hypertonic ( 7.5 per cent) saline at room temperature.

After injection of the first $2.0 \mathrm{ml}$ of solution the patient complained of a severe pain in both groins, whereupon intravenous innovar was given. When the innovar was effective a further $13.0 \mathrm{ml}$ of the saline solution was injected over a tensecond period. The spinal needle was withdrawn and the patient was placed in the supine position. No change in cardiac rate or rhythm was observed and the blood pressure remained stable.

The patient complained bitterly of a crushing type of pain in the lower extremities and it was noted that there was a total motor paresis of the lower limbs. A level of skin anaesthesia to pin prick up to the tenth thoracic dermatome was observed.

On transfer to the recovery room, $10 \mathrm{mgm}$ of morphine sulphate intravenously was needed to sedate the patient.

Sensory loss disappeared half an hour after the subarachnoid injection and motor power began to return; this was complete in approximately one and a half hours.

Catheterization of the bladder was necessary once on the evening of the day of the procedure.

\section{Results}

Within two hours of the procedure the patient had lost the continuous preoperative pain in the right ankle. The color of the legs was improved and there was loss of the cyanotic mottling of the extremities which became warm to touch.

One of the gangrenous toes appeared to be revascularized and the other recovered later except for a small area at the very tip which was beyond return at the outset. 
The patient's exercise tolerance increased and she was able to walk some fifty yards without claudication before discharge from hospital.

No permanent sequelae followed; the patient did have slight vertigo on standing for the first postoperative day; this was thought to be due to postural hypotension but blood pressure recordings did not confirm this.

No headaches occurred and there were no signs or symptoms of meningeal irritation.

After discharge from hospital the patient unfortunately had a flu-like attack which kept her restricted, however, she was able to use a foot-pedalled sewing machine during this time and was pain free until the forty-ninth postoperative day when pain returned in the right ankle.

Seen at the hospital after return of pain, the feet were cool and the tocs of the left foot were slightly cyanosed. However, there were no signs of gangrene. It was decided to repeat the procedure of osmotic neurolysis and this was performed the following day under heavier sedation than previously.

On this occasion the procedure was as before except that $20 \mathrm{ml}$ of saline $(7.5$ per cent) at room temperature was introduced into the subarachnoid space. The same motor and sensory losses occurred and declined as before; six hours after the block, the feet were warm and pain free.

The patient was discharged on the second postoperative day with instructions to exercise her extremities to the point of tolerance.

\section{Discussion}

Stovall King et al., ${ }^{6}$ concluded, following experiments with hypertonic saline at room temperature, that $\mathrm{c}$ fibre blockade could be the mechanism of pain relief following intrathecal hypertonic saline solutions.

In the case presented, although there had been surgical sympathectomy performed, the result of the saline block appeared to produce a marked sympathetic block and exercise tolerance was greatly improved.

This c fibre block, by producing a sympathetic block might result in the relief of pain of claudication, however, this patient had such severe vascular disease that even with complete sympathetic block it would be reasonable to assume that there would still be tissue ischaemia and therefore pain on exercise. As pain on exercise was greatly diminished it leads one to believe that a block of A-Delta fibres carrying pain was also produced by the intrathecal saline. It is noted that unlike previous reports, all types of nerve fibres appeared to be affected but for varying lengths of time.

It will be of interest to see whether this patient, given more time, will develop a collateral circulation capable of maintaining adequate blood supply to the limbs.

So far as the procedure is concerned it is noted by Matthews and confirmed by this writer that patients undergoing neurolysis suffer from pain of the severest nature during injection of the saline. This has led to the performance of subsequent procedures under general anaesthesia.

In view of Hitchcock's ${ }^{7}$ report on the ECG changes after intrathecal hypertonic saline, lumbar intrathecal injections have been performed here under epidural 
block with the intention of blocking sympathetic fibres and so preventing stimulation by the saline solution.

\section{SUMMARY}

A case of severe vascular insufficiency of the lower extremities is presented.

Despite extensive and repeated vascular surgical procedures the patient was severely disabled and was suffering pain and gangrene.

Subarachnoid osmotic neurolysis using 7.5 per cent saline at room temperature was carried out on two occasions giving good, though temporary relief of signs and symptoms without demonstrable permanent complications.

\section{RÉSUMÉ}

Nous présentons un cas d'insuffisance vasculaire prononcée des extrémités.

En dépit de chirurgie vasculaire extensive à plusieurs reprises le malade était presque impotent, était souffrant et présentait de la gangrène.

A deux reprises, nous avons pratiqué une neurolyse sous-arachnoïdienne avec une solution salée à 7.5 pour cent à la $\mathbf{T}^{0}$ de la chambre; ce traitement a apporté un bon soulagement, bien que temporaire, des signes et des symptômes; il n'a pas produit de complications permanentes visibles.

\section{REFERENCES}

1. Hrxcrcock, E. Hypothermic Subarachnoid Injection for Intractable Pain. Lancet. 1: 1133-1135 (1967).

2. Matthews, G. J. \& Pace-Florida, A. Intrathecal Cold Saline for the Relief of Intractable Pain. C.M.A.J., 103: 1143-1146 (1970).

3. Hiтcicock, E. Osmolytic Neurolysis for Intractable Facial Pain. Lancet. 1: 434-436 (1969).

4. Coles, J. C. Personal Communication.

5. BARR, H. Personal Communication.

6. Stovall King, J.; JeWett, D. L.; \& Sundberg, H. R. Unpublished.

7. Hrтckcock, E. Electrocardiographic Changes after Intrathecal Hypertonic Saline Solution. Lancet. 11: 1083-1084 (1968). 